Atmos. Chem. Phys., 10, 877-893, 2010

www.atmos-chem-phys.net/10/877/2010/

(C) Author(s) 2010. This work is distributed under

the Creative Commons Attribution 3.0 License.

\title{
Cluster analysis of the impact of air back-trajectories on aerosol optical properties at Hornsund, Spitsbergen
}

\author{
A. Rozwadowska ${ }^{1}$, T. Zieliński ${ }^{1}$, T. Petelski ${ }^{1}$, and P. Sobolewski ${ }^{2}$ \\ ${ }^{1}$ Institute of Oceanology, Polish Academy of Sciences, Sopot, Poland \\ ${ }^{2}$ Institute of Geophysics, Polish Academy of Sciences, Warsaw, Poland \\ Received: 30 June 2009 - Published in Atmos. Chem. Phys. Discuss.: 20 July 2009 \\ Revised: 27 November 2009 - Accepted: 2 December 2009 - Published: 1 February 2010
}

\begin{abstract}
In this paper, spectra of aerosol optical thickness from the AERONET (AErosol RObotic NETwork) station at Hornsund in the southern part of Spitsbergen were employed to study the impact of air mass history on aerosol optical thickness for wavelength $\lambda=500 \mathrm{~nm}-\mathrm{AOT}(500)-$ and the Ångström exponent. Backward trajectories computed, using the NOAA HYSPLIT model, were used to trace air history. It was found that in spring, the changes in AOT values over the Hornsund station were strongly influenced by air mass trajectories 8 days or longer in duration, arriving both in the free troposphere and at an altitude of $1 \mathrm{~km}$ above sea level. Nevertheless, free tropospheric advection was dominant. AOT variability in summer was best explained by the local direction and speed of advection (1-day trajectories) and was dominated by the effectiveness of cleansing processes. During the ASTAR 2007 campaign, the aerosols near Hornsund displayed low AOT values ranging from 0.06 to 0.09 , which is lower than the mean AOT(500) for spring seasons from 2005 to $2007(0.110 \pm 0.007$; mean \pm standard deviation of mean). 9 April 2007 with AOT(500) $=0.147$ was exceptional. The back-trajectories belonged to clusters with low and average cluster mean AOT. Apart from the maximum AOT of 9 April 2007, the observed AOT values were close to or lower than the means for the clusters to which they belonged.
\end{abstract}

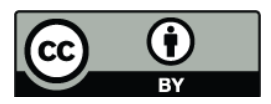

Correspondence to: A. Rozwadowska (ania@iopan.gda.pl)

\section{Introduction}

Atmospheric aerosols originate from a wide variety of sources in both marine and continental environments. Aerosol content varies significantly depending upon the airmass source and history. The Arctic is characterised by a low aerosol load; however, aerosol optical thickness increases considerably in late winter and spring (Arctic haze) and during direct advections of polluted air from lower latitudes in other seasons (e.g. Herber et al., 2002; Tomasi et al., 2007; Quinn et al., 2007; Engvall et al., 2008).

Nearly all pollution in the high Arctic originates from more southerly latitudes. Local pollution sources are small and limited to the vicinity of the Arctic Circle (Law and Stohl, 2007). Long-range transport of aerosols and their gaseous precursors is most abundant in winter and spring, when the southward shift of the Arctic front facilitates the advection of polluted air from mid-latitudes, mainly from Europe and Asia. The stable atmosphere and relatively low scavenging by clouds and precipitation are additional factors influencing the effectiveness of the transport of aerosols and gaseous precursors (Quinn et al., 2007). The end of the polar night causes the generation of aerosols from gaseous precursors as a result of photochemically induced reactions. In summer, the Arctic front moves further north, making advection of air from mid-latitudes more difficult; also, the dominant direction of circulation changes. In winter, the mean circulation is characterised by fast low-level transport from northern Eurasia across the Arctic to North America, whereas in summer the typical pathway leads from the North

Published by Copernicus Publications on behalf of the European Geosciences Union. 
Atlantic Ocean across the high Arctic towards the North Pacific Ocean. Moreover, the summer transport is slower (Law and Stohl, 2007). In spring (i.e. mid-April to May) almost the whole Arctic region is dominated by high-pressure situations. In Svalbard this results in a typically persistent airflow from the Arctic, and slow transport from the northern part of Russia, Scandinavia and the Atlantic (Eneroth et al., 2003; Engvall et al., 2008). Also, biomass burning in Eurasia and North America and the advection of desert dust play an important role in Arctic air pollution (Stohl et al., 2006; Treffeisen et al., 2007; Generoso et al., 2007; Tomasi et al., 2007; Stone et al., 2007). Arctic aerosols can also be influenced by volcanic activity (Law and Stohl, 2007; Nagel et al., 1998; Tomasi et al., 2007); the volcanic regions closest to the Arctic are the Kamchatka Peninsula and Alaska.

Natural, local Arctic sources of aerosol are usually far less effective with regard to AOT enhancement than long-range transport. Local Arctic aerosols consist of sea salt particles (Petelski and Piskozub, 2006), mineral dust, the oxidation products of dimethyl-sulphide emitted from the sea surface (Hillamo et al., 2001) and insoluble organic particles derived from the surface microlayer of the ocean by bubble bursting (Leck and Bigg, 2005). Analysing a three-year set of simultaneous measurements from Barrow, Quinn et al. (2002) found that sea salt and sulphate aerosol were the dominant ionic species. However, local Arctic sources can also be efficient. Mulcahy et al. (2008) found that under moderate-tohigh wind conditions, the sea-spray aerosol optical thickness was comparable to that associated with pollution plumes over oceanic regions.

Aerosol sources related to anthropogenic activity and the transportation pathways have been investigated at different Arctic stations such as Alert (Canadian Northern Territories; Lin et al., 2001) and Station North, Greenland (Heidam et al., 2004). Stohl et al. (2002) performed a one-year simulation of the transport of six passive tracers, released over the continents according to an emission inventory for carbon monoxide. They found that the European contribution was several times higher than the Asian and American ones. The pollution sources have been identified, but models do not agree on the importance of certain pollution elements; for example, recent modelling studies yield conflicting results on whether southern Asia is a significant source of pollutants to the Arctic or not (Quinn et al., 2007). Besides, only a small number of papers discuss long-range transport and its impact on aerosol optical properties, and this is especially true in the European Arctic (Herber et al. 2002).

Pollution can be advected to the Arctic both in the boundary layer and the free troposphere (Khattatov et al., 1997; Myhre et al., 2007; Quinn et al., 2007), and its residence time in the atmosphere depends on a number of factors such as scavenging by cloud and precipitation (e.g. Khattatov et al., 1997). In order to analyse the long-range transport of pollutants to the Arctic, five- or ten-day back-trajectories are most often used (Eneroth et al., 2003; Lin et al., 2001). Eneroth et al. (2003) suggested that five-day trajectories are not long enough to explain some of the $\mathrm{CO}_{2}$ variability.

The aim of this work was to determine the contribution of aerosol transport to aerosol optical thickness and Ångström exponent variability in the southern part of Svalbard, to identify the main sources and paths of air advection to the South Svalbard area and to determine basic aerosol optical characteristics for each of them. The authors also determined the arrival altitude of advection and the length of back-trajectories that best explain the variability in the aerosol optical thickness at the Hornsund station. Additionally, the aerosol optical properties measured at the Hornsund station during the ASTAR 2007 campaign are presented. The paper is intended mainly as a climatological background to the aerosol measurements performed at Hornsund during the ASTAR campaign.

The cluster analysis of air back-trajectories employed in the paper is a technique widely used to identify transport patterns and potential sources of both anthropogenic pollution and natural constituents of the atmosphere, including atmospheric aerosols (e.g. Abdalmogith and Harrison, 2005; Owega et al., 2006; Katragkou et al., 2009; Xia et al., 2007). It is also used to determine how aerosol optical properties observed over the station differ depending on source region and transport pathways (Xia et al., 2007; Toledano et al., 2009; Gogoi et al., 2009; Yan et al., 2008). This method has been used for various parts of the world, but only one paper concerns the European High Arctic. Eneroth at al. (2003) applied the cluster analysis of five-day back-trajectories to identify distinct transport patterns for Ny Ålesund (Svalbard) and compare the trajectory clusters to $\mathrm{CO}_{2}$ measurements in order to study the extent to which different atmospheric flow patterns influence the variability in atmospheric $\mathrm{CO}_{2}$. In the present paper, cluster analysis of back-trajectories is used to analyse the variability in aerosol optical properties at Hornsund, Svalbard.

\section{Methodology}

\subsection{Data}

The authors used aerosol data from the AERONET (AErosol RObotic NETwork) station at Hornsund from the period 2005-2008. The measurements at Hornsund were made from late March to late September. The Hornsund station provided total aerosol optical thickness (AOT) measurements for selected wavelengths $(340,380,440,500,675,870,1020 \mathrm{~nm})$, water vapour content in the atmosphere as well as the contributions of the fine and coarse modes of the aerosol size distribution to the total AOT for $\lambda=500 \mathrm{~nm}\left(\mathrm{AOT}_{\mathrm{f}}\right.$ and $\mathrm{AOT}_{\mathrm{c}}$, respectively). For clear sky conditions, measurements were made 6 times an hour (intervals of 6 to $15 \mathrm{~min}$ between measurements). In cloudy conditions, the measurements were distributed unevenly during the day. The AOT measurement 
accuracy is 0.02 for ultraviolet and 0.01-0.02 for visible solar radiation $(\lambda>380 \mathrm{~nm})$ (Smirnov et al., 2000). For the purpose of this paper, the authors used mainly AOT data. AOT $_{\mathrm{f}}$ and $\mathrm{AOT}_{\mathrm{c}}$ are the respective AOT values due to fine and coarse mode aerosol attenuation. The modes used in this instance by AERONET are defined optically. The coarse mode spectral variation is approximately neutral. Details of the algorithm for the spectral discrimination between coarse and fine mode optical depth can be found in O'Neill et al. (2003).

During the ASTAR 2007 campaign, which lasted from 28 March to 16 April, a number of additional measurements were made at Hornsund. In this paper, the authors used aerosol concentration and size distribution from measurements with a Classical Scattering Aerosol Spectrometer Probe CSASP-100-HV-SP.

Like any other automated algorithm, the AERONET cloud screen algorithm (Smirnov et al., 2000) is not $100 \%$ successful. The original spectra obtained from AERONET were additionally cloud screened. Since the authors did not have independent Cirrus cloud measurements for further quality assessment, the nature of the temporal changes in $\mathrm{AOT}, \mathrm{AOT}_{\mathrm{f}}$ and $\mathrm{AOT}_{\mathrm{c}}$ as well as meteorological observations were used (Hornsund is WMO station No. 01003). Cases when greater temporal variability in AOT was caused only by coarse particles, indicating the high probability of thin Cirrus clouds or drifting snow crystals, were rejected. Such an approach is justified by the high correlation of the elevated concentration of coarse mode aerosol (measured with CSASP-100HV-SP) with blowing snow and the cases of precipitation observed during the ASTAR campaign (Rozwadowska et al., 2008). Moreover, the increase or strong temporal variations in coarse mode AOT were often accompanied by a chopped dataset, when only a few measurements were made during the day (signs of a cloudy day) and occurred near breaks in the measurements (edges of clouds). Both cloud particles and blowing snow particles belong to the coarse mode. Sandstorms, another source of coarse mode particles, are unlikely at Hornsund. The only source of aerosol coarse mode particles is the ocean, but such cases must be related to strong winds blowing in from the ocean. Therefore, cases when higher AOT temporal variability was caused only by coarse particles and could not be justified by a storm on the ocean were rejected.

Days during which a minimum of five measurements were made were chosen for the subsequent analyses. For each day, the average Ångström exponent $(\alpha)$ and average AOT(500) were calculated. AOT(500) stands for the aerosol optical thickness for the wavelength $\lambda=500 \mathrm{~nm}$. The Angström exponent is the slope of the AOT spectrum presented in the $\log -\log$ scale. It is defined as

$\operatorname{AOT}(\lambda)=\operatorname{AOT}\left(\lambda_{0}\right) \cdot\left(\frac{\lambda}{\lambda_{0}}\right)^{\alpha}$

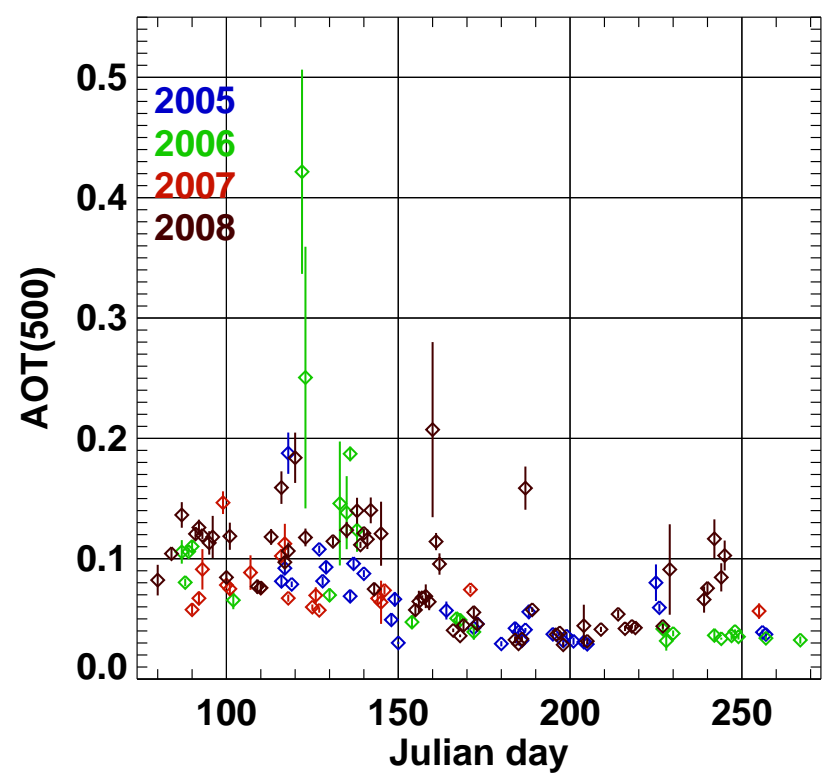

Fig. 1. Temporal variations of AOT between 2005 and 2008 in Hornsund. Symbols and whiskers show daily means and standard deviations (variability of AOT within a given day).

where $\lambda_{0}$ is the reference wavelength and $\lambda_{0}=1000 \mathrm{~nm}$. The Ångström exponent was calculated for the spectral range from 440 to $870 \mathrm{~nm}$,

Figure 1 shows the whole set of daily means of AOT at Hornsund used in the present paper. A detailed discussion of the seasonal variability in AOT and $\alpha$ at Hornsund will be given in a separate paper (Rozwadowska and Sobolewski, 2010). The error of the daily average AOT is lower than 0.005 , with the exception of several cases of high AOT and significant daily variability. Typical errors of the daily average $\alpha$ are 0.07 for $\operatorname{AOT}(500)=0.12,0.1$ for $\operatorname{AOT}(500)=0.07$ and 0.2 for $\operatorname{AOT}(500)=0.04$. The daily variability and nonlinearity of the spectrum (on a log-log scale) are the main causes of the average $\alpha$ error. Hereafter, AOT(500) denotes the daily AOT means for $\lambda=500 \mathrm{~nm}$ and $\alpha$ the Ångström exponent calculated for the spectral range from 440 to $870 \mathrm{~nm}$; $\alpha$ is also a daily mean.

\subsection{Backward trajectories}

Backward trajectories computed by means of the NOAA HYSPLIT model (Draxler and Rolph, 2003) were used to trace the air history. The mid-point of the aerosol-measuring period on a given day was selected as the trajectory arrival time input to HYSPLIT on that day. For calculations, the 'Reanalysis' database was used. "Reanalysis", in this case, means the name of a dataset in the HYSPLIT services to calculate trajectories, i.e. global NOAA-NCEP/NCAR pressure level reanalysis data archives reprocessed into the HYSPLIT compatible format (NCAR/NCEP reanalysis project; Kalnay et al., 
1996; Draxler et al., 2009). The global data are given on a latitude-longitude grid ( 2.5 degrees) at 17 pressure levels (18 sigma levels). The time resolution of the data is $6 \mathrm{~h}$.

The trajectories were calculated for three arrival heights: $1 \mathrm{~km}, 2.5 \mathrm{~km}$ and $5 \mathrm{~km}$ above sea level. These heights are comparable to those used by Engvall et al. (2008) for Ny Ålesund. It must be noted that these trajectories, in general, change altitude as a function of transit time and that these heights are only those at which the air arrives at the station. The selection of $1 \mathrm{~km}$ as the lowest level resulted from the orography around the station. The fjord is surrounded by hills of 500 to $1000 \mathrm{~m}$ in height above sea level (highest peak $1431 \mathrm{~m}$ ) and, thus, lower trajectories, even if they are calculated properly, will be significantly influenced by the orography.

The $5 \mathrm{~km}$ level at the station is in the free troposphere (FT), and the $1 \mathrm{~km}$ height at the station is likely to be in the boundary layer (BL). There is a lack of data regarding the boundary layer thickness over Hornsund, but it is not a typical Arctic $\mathrm{BL}$ over an ice-covered sea. The station is surrounded by a varied landscape: fjord and ocean, glaciers, tundra and rocks. Moreover, the station is located at the mouth of the fjord to the warm ocean. 1-2 km north of the station, there is a mountain peak c. $500 \mathrm{~m}$ high. Most likely, the boundary layer top often exceeds $1000 \mathrm{~m}$ above sea level. The spring occurrence of Cumulonimbus clouds confirms the presence of a relatively thick boundary layer, which is probably similar to that in Kongsfjorden (Spitsbergen). Engvall et al. (2008) assumed the thickness of the boundary layer in Ny Ålesund (Kongsfjorden) to be c. $2 \mathrm{~km}$ for April to June. They defined the boundary layer limits using the height of the cloud tops.

To check the representativeness of the trajectories arriving at Hornsund for the Hornsund area, trajectories for points shifted by $2.5^{\circ} \mathrm{E}$ and $\mathrm{W}$ and $0.5^{\circ} \mathrm{N}$ and $\mathrm{S}$ from Hornsund were calculated for the same altitudes as at Hornsund besides the trajectories ending at Hornsund itself. As far as trajectories arriving at one altitude are concerned, in $70 \%$ of cases $3-$ 4 of the 4 trajectories arriving at points around Hornsund are very similar to those simultaneously reaching Hornsund itself at the same altitude; in another $23 \%$ of cases, 2 of the 4 trajectories resemble those at Hornsund. Comparison of sets of trajectories arriving simultaneously at all 3 altitudes shows that in $72 \%$ of cases at least 2 trajectory sets reaching the points around Hornsund are in agreement at all 3 altitudes with the trajectories for Hornsund itself and in $40 \%$ of cases at least 3 sets are in such agreement. For certain cases with strong divergence, trajectories were also calculated with a denser grid. It was found that strong spatial trajectory divergences also occur for a denser meteo grid ( $1^{\circ}$ of latitude and longitude). The spatial distribution of additional points with trajectories concurring with those for Hornsund is variable. We must remember that $120 \mathrm{~km}$ is already within the synoptic scale and, thus, the trajectories can differ.

Only the trajectories for Hornsund were used in the later calculations.

\subsection{Cluster analysis}

Cluster analysis was used in the paper to classify backward air trajectories into groups of similar history, i.e. similar direction of advection and velocity of air movement. It was shown that the trajectory clusters are associated with the features of large-scale atmospheric circulation (Dorling et al., 1992). The non-hierarchical clustering algorithm, described by Dorling et al. (1992), was employed in this study. The authors used the dataset of geographical coordinates of air parcel back-trajectories, which reached the Hornsund station, calculated at 1-h intervals for a period of time between 0 to $192 \mathrm{~h}$ prior to arrival above the station.

Prior to the cluster analyses, the geographical coordinates were converted to $\mathrm{x}$, $\mathrm{y}$ on a plane using the azimuthal equidistant projection with the central point being the geographical position of the Hornsund station. It was assumed that the distortion related to the projection had a secondary impact on the classification. The projection is equidistant along the "meridians" (in this nomenclature Hornsund - the tangent point of the projection - is located at the pole); however, there is some distortion along some other lines. It is the greatest along the "parallels" and increases with angular distance from the tangent point from $0.4 \%$ for $20^{\circ}, 2.0 \%$ at $30^{\circ}, 4.6 \%$ at $40^{\circ}, 8.5 \%$ at $50^{\circ}$ and $13.8 \%$ at $60^{\circ}$. The cases given are extreme. The error decreases when the points are not on the same 'parallel'. The majority of trajectories are within $40^{\circ}$ and only some exceed $60^{\circ}$. Besides, the respective points of two trajectories are rarely on the same "parallel".

The calculated Euclidean distances $d_{i j}$ between the $i$-th trajectory and a typical (mean) $j$-th cluster trajectory are defined as follows:

$d_{i j}^{2}=\sum_{l=1}^{l=N_{l}} \sum_{k=1}^{k=N_{h}}\left[\left(x_{i k l}-X_{j k l}\right)^{2}+\left(y_{i k l}-Y_{j k l}\right)^{2}\right]$

where

- $k$ - index equal to the air pass time from a given trajectory point to Hornsund expressed in hours,

- $N_{h}$ - trajectory length expressed by the number of hours used in clustering,

$-l-$ the number of trajectory arrival level considered,

- $N_{l}$ - the number of trajectory levels used in clustering,

- $x_{i k l}, y_{i k l}$ - coordinates on the plane of the $k$-th point of the $i$-th trajectory reaching the $l$-th height above the station,

- $X_{j k l}, Y_{j k l}$ - coordinates on the plane of the $k$-th point of an average trajectory of the $j$-th cluster reaching the $l$-th height above the station. 
The algorithm minimized the following factor:

$f=\sum_{j=1}^{j=N_{c}} \sum_{i=1}^{i=N_{t j}} d_{i j}^{2}$

where $i$ is the number of the next trajectory in the $j$-th cluster, $N_{t j}$ denotes the number of trajectories in the $j$-th cluster, and $N_{c}$ is the number of clusters.

Clustering was performed for three "seed" trajectory files, trajectories for single air arrival altitudes $(1,2.5$ or $5 \mathrm{~km}$ above sea level), combinations of two altitudes and for trajectories arriving at three height levels simultaneously. Clustering was done for trajectories of lengths between $24 \mathrm{~h}$ ( 1 day) to $192 \mathrm{~h}$ (8 days). In this study, three types of seed files were applied. The first seed file included all trajectories from a given season (seed file 1). The second included a selection of trajectories from a given season with a range of different trajectory shapes (seed file 2). The third seed file (seed file 3) consisted of "artificial" back-trajectories, which originated at 45 or $65^{\circ} \mathrm{N}$ and which after eight days reached Hornsund. Four (two short and two long) of these "radii" were directed towards Asia, two to Europe, two to the Atlantic Ocean, to North America and the last two towards the Bering Strait. With trajectory clustering at several levels simultaneously, a combination of these "radii" was used as a seed file.

We mixed the levels in the distance measure to represent the advection in the entire column of the lower and middle troposphere. Pollution advection may occur at different altitudes. The similarity of trajectories arriving at a point at a given altitude may not be relevant to the trajectories arriving at that instant at other altitudes. In our cluster analysis, each cluster member is represented by 1, 2 or 3 trajectories together.

Only trajectory coordinates have been used in the clustering algorithm, while additional factors such as trajectory height (except for the arrival height at Hornsund), topography, land cover, sea ice, atmospheric stability, precipitation or certain events (such as fires) have not been explicitly included. However, some of these factors are related to geographical coordinates. These factors could be significant to the aerosols on the trajectory arriving over Hornsund, but we do not have enough data to introduce another parameter to the clustering. This paper is a first approach to the problem for the Hornsund station.

Owing to significant seasonal differentiation of the Arctic aerosol properties, the spring data (in this paper March, April, May - Julian days up to 147) and summer data (midJune to mid-September, Julian days from 165 to 266) were analysed separately. Figure 1 shows temporal variations in AOT during the measurement years at the Hornsund station. The mean values AOT(500) for spring and summer are $0.110 \pm 0.007$ (mean and standard deviation of the mean) and $0.048 \pm 0.003$, respectively. The transition period (Engvall et al., 2008) was ignored.

\subsection{Relative variance}

The aim of the cluster analysis of air trajectories was to determine the importance of aerosol transport in AOT and Ångström exponent variability in the southern part of Svalbard. We attempted to determine the height of air arrival and the length of the back-trajectory that best explain the variability of AOT in Hornsund. To solve this problem, the relative variance of AOT was analysed. The relative variance of AOT is defined by the following formula:

$\operatorname{rv}(\mathrm{AOT})=\frac{\sum_{j=1}^{j=N_{\mathrm{c}}} \sum_{i j=1}^{i j=N_{j}}\left(\mathrm{AOT}_{i j}-\langle\mathrm{AOT}\rangle_{j}\right)^{2}}{\sum_{i=1}^{i=N}\left(\mathrm{AOT}_{i}-\langle\mathrm{AOT}\rangle\right)^{2}}$,

where $N$ is the total number of cases (measurement days), $N_{\mathrm{c}}$ is the number of clusters, $N_{j}$ the number of cases from the $j$-th cluster, $\mathrm{AOT}_{i j}$ is AOT for the $i$-th case from the $j$-th cluster, $<\mathrm{AOT}\rangle_{j}$ is the average AOT for all cases from the $j$-th cluster. Low values of rv(AOT) are found if atmospheric transport, as specified by the clusters, is able to explain the variance.

In the variance calculations, the AOT values deviating most from the seasonal average were rejected, e.g. 2 and 3 May 2006 (respective Julian days 122 and 123) and 5 July and 29 August 2008 (respective Julian days 187 and 241; see Fig. 1). The inclusion of these cases in particular clusters would have had a strong impact on the relative variance of AOT, which would have masked the contribution of other cases. The exceptionally high AOT cases of 2 and 3 May 2006, caused by farmland fires in Eastern Europe, were discussed by Myhre et al. (2007). However, the discussion of the particular cases of trajectory division in clusters (Sects. 3.1 and 3.2) includes all AOT cases, since the outliers influence the mean AOT and variance values only for their own clusters. In this case, taking days with very high AOT values into consideration does not alter the picture of the situation as much as in the relative variance analysis. Moreover, the placement of these outliers in the clusters is discussed in the text.

The relative variance of AOT decreases strongly as the number of clusters increases. However, the number of oneelement clusters also increases along with the increase in the number of clusters. Taking into consideration the relatively low number of measurement days in both seasons (about 60 per season) and the great number of possible combinations of trajectory shapes and directions at 3 levels, we decided that division into 10 clusters would be optimal for the relative variance analysis. The number of clusters was made constant so as to make all the clustering cases under analysis comparable. One of the criteria, for selecting the number of clusters, involves the points of the strong increase in the minimized factor (Eq. 3) with the decrease in the number of clusters (Dorling et al., 1992). In our analysis, one of the "breaks" in the plot of the minimized factor in the function 
of a number of clusters usually occurred in the range 7 to 11 clusters.

One-element "clusters" have an average variance of zero. In order to check their impact on the relative variance discussed in this paper, relative variance was also calculated with zero variance in these clusters replaced with values equal to three times the variance for the entire season (without clustering). The differences in relative variance were negligible.

\section{Results}

\subsection{Back-trajectory clusters for Hornsund station}

In this section, we identify the main sources and paths of advection to southern Spitsbergen and relate them to aerosol optical properties. Since this paper investigates the dependence of aerosol optical properties on air mass trajectories, the criterion for choosing the optimum trajectory division into clusters involves the greatest decrease in AOT variance. This section presents the results of the trajectory division, optimum for our dataset, into 10 clusters (compare Sect. 3.3). For the current AOT dataset, the optimum trajectory division was obtained using the clustering of 5-day trajectories arriving at an altitude of $5 \mathrm{~km}$ above sea level in spring and of 1-day trajectories at 2.5 and $5 \mathrm{~km}$ in summer, both for seed file 2 (compare Sect. 2.3). For each cluster source the trajectory areas are discussed as well as the directions of air mass advections and the synoptic situation at the moment of air mass arrival over the station. For the synoptic discussion, a calendar of circulation types for Spitsbergen is used (Niedźwiedź, 2009). Classification of circulation types is based on surface synoptic maps and takes into account the direction of the geostrophic wind and the kind of pressure pattern (anticyclonic, cyclonic). The geostrophic wind direction illustrates the position of a cyclone or anticyclone with respect to southern Spitsbergen. When discussing the results of the impact of air back-trajectories on aerosol optical properties investigations, we must remember that the sun photometer method of measuring AOT precludes measurements on cloudy days. This favours anticyclonic weather conditions and reduces the number of measurement days. In this paper, we used data from four years of measurements, but for the cluster analyses we used only 66 spring days and 60 summer days.

\subsubsection{Spring}

In spring, the optimum trajectory division was obtained using the clustering of 5-day trajectories arriving at $5 \mathrm{~km}$. The 5-day trajectories for particular clusters and the 5-day trajectories of cluster members are presented in Fig. 2. Additionally, Fig. 2 shows full 8-day trajectories arriving at heights of $1 \mathrm{~km}, 2.5 \mathrm{~km}$ and $5 \mathrm{~km}$ above sea level of days from particular clusters. This gives the full advection picture within particular clusters. In general, the advection of an air mass at any altitude may impact on AOT values. Moreover, the similarity of the trajectories that arrive at one altitude does not necessarily imply the similarity of trajectories at other altitudes.

The most abundant cluster is the central one, number 4 (19 days out of 66). It includes trajectories with very different source areas and directions, and also large curvatures. A common feature of the trajectories is the relatively long air mass residence time over the Arctic Ocean. There is no characteristic direction of advection on the synoptic maps for this cluster. Anticyclonic advection and low pressure gradients are dominant.

Clusters 2 (9 members), 7 (6 members) and 8 (6 members) are North American. Trajectories arriving at $5 \mathrm{~km}$ come from Labrador (mainly cluster 8), northern Canada, Alaska (mainly cluster 2 ) and the Canadian Arctic. Lower trajectories $(2.5$ and $1 \mathrm{~km})$ come mainly from various parts of the Arctic Basin and adjacent seas and also from over the Asian Arctic and northern Siberia, especially in cluster 2. No dominant circulation type for cluster 2 at the instants of trajectory arrivals was found. Advection (the geostrophic wind) is mainly from the $\mathrm{N}$ and $\mathrm{NE}$ in both cyclonic and anticyclonic regimes. An easterly cyclonic advection was dominant in cluster 7 . For cluster 8 the synoptic maps show the dominance of anticyclonic circulations, but there is no dominant geostrophic wind direction.

Clusters 3 (10 members), 5 (3 elements) and 9 (4 members) are Eurasian. In all these clusters air arrives at Hornsund within an anticyclonic circulation: $\mathrm{E}$ in cluster 9, NE, $\mathrm{E}$ and $\mathrm{N}$ in cluster 3 . An anticyclonic circulation with a low pressure gradient was found in cluster 5 .

Cluster 1 ( 7 members) is northerly. These are the trajectories that arrive from over the Pacific and pass rapidly across the entire Arctic. The atmospheric circulation during the AOT measurements was mostly anticyclonic. The dominant air mass advection directions to Hornsund (geostrophic wind), determined using the surface synoptic maps, were NE and $\mathrm{N}$.

The clusters presented are not very abundant; however, their representativeness is confirmed by the fact that in most cases they have trajectories from different years and/or months. Clusters 10 and 6 are 1-member clusters. These trajectories are sufficiently different that the reduction in the number of clusters to 8 did not lead to the 1-member clusters being eliminated. With the decrease in the number of clusters, the algorithm links similar clusters but does not force the elimination of 1-member clusters. Obviously, such clusters are not statistically significant and can be treated as outliers.

\subsubsection{Summer}

In summer the optimum division of trajectories was obtained by clustering the 1-day trajectories arriving at 2.5 and $5 \mathrm{~km}$. The average 1-day trajectories for particular clusters and 

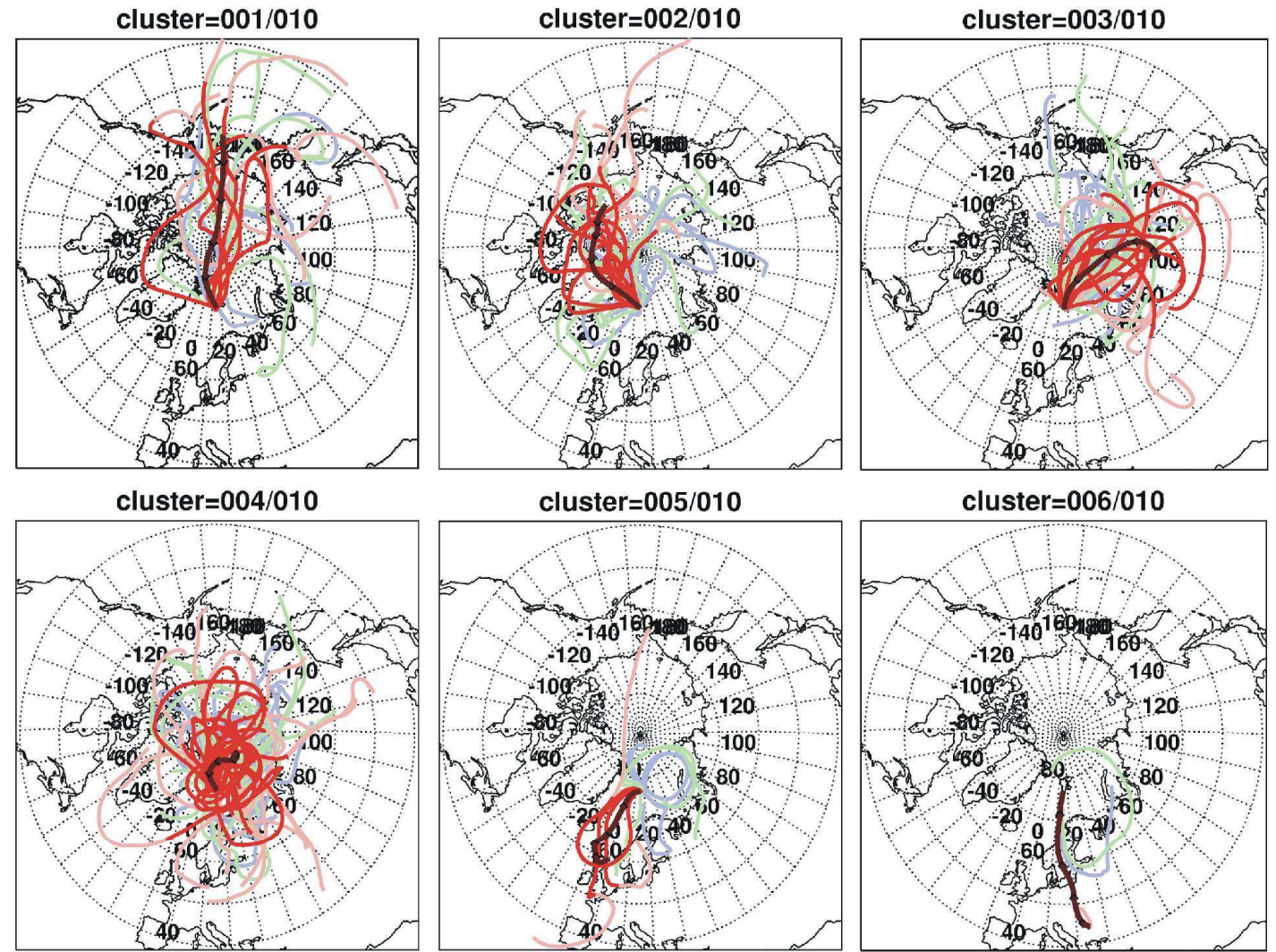

cluster $=006 / 010$
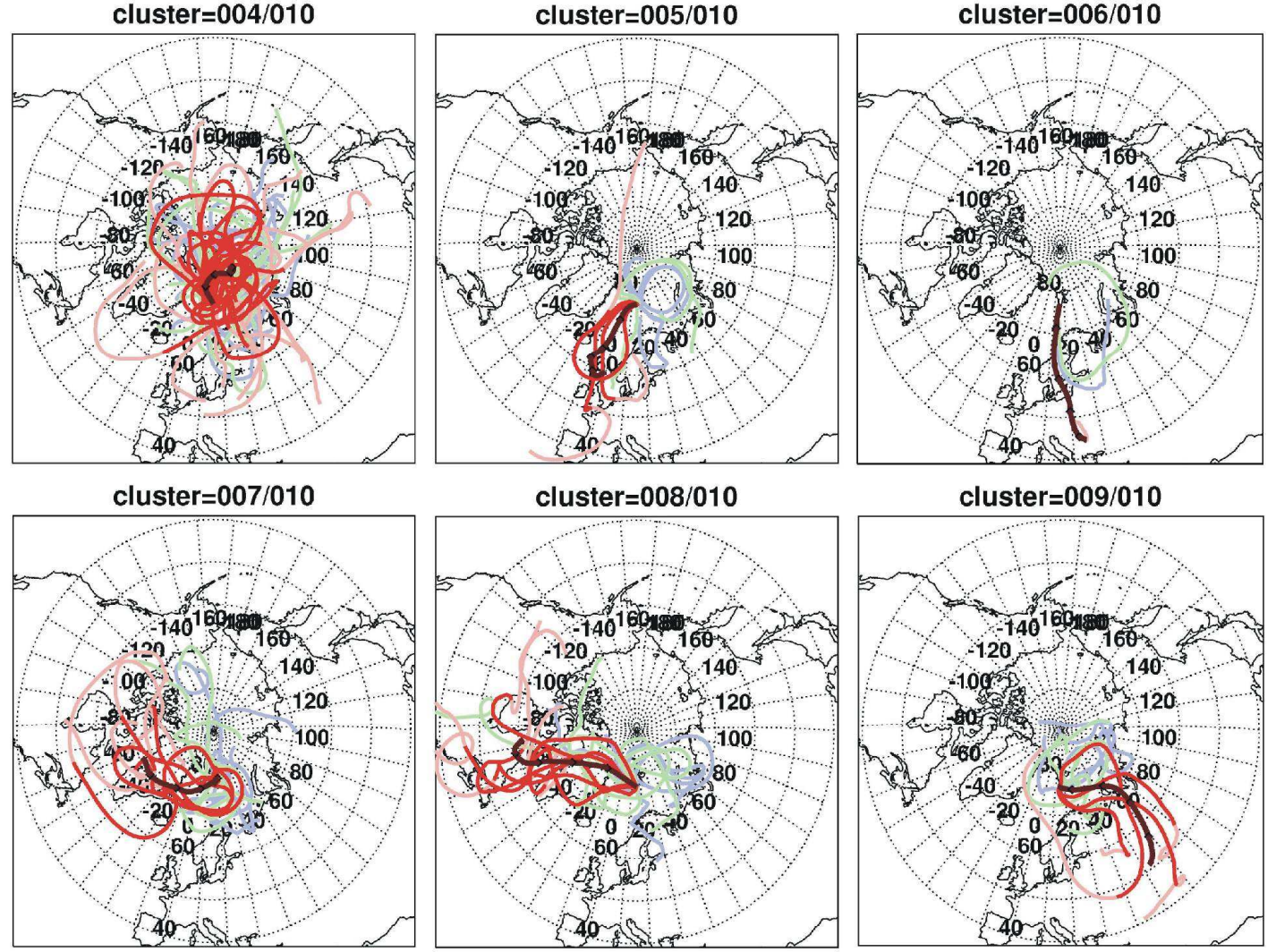

cluster $=010 / 010$
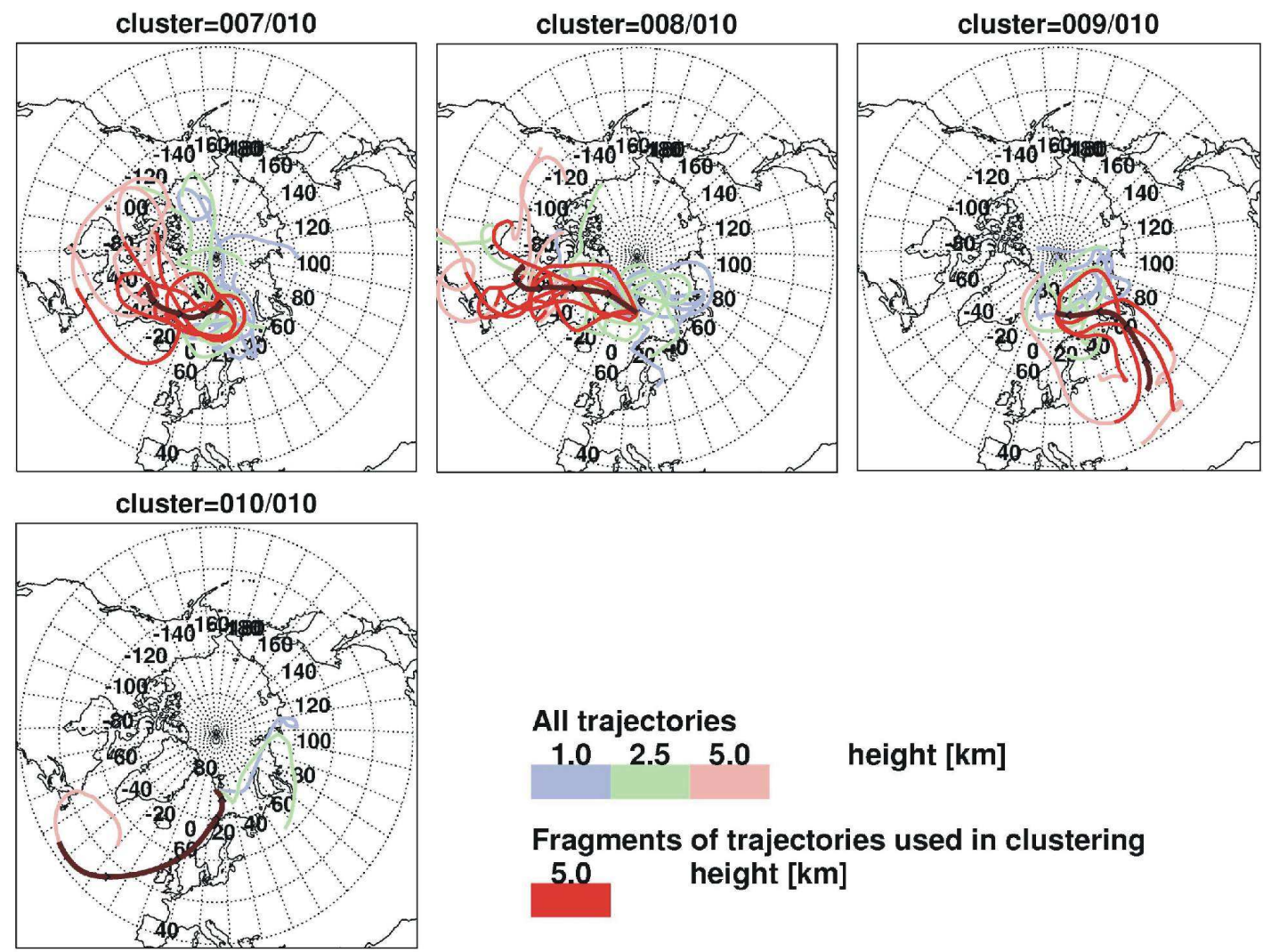

\section{All trajectories}

$\begin{array}{llll}1.0 & 2.5 & 5.0 & \text { height }[\mathrm{km}]\end{array}$ Fragments of trajectories used in clustering
$5.0 \quad$ height $[\mathrm{km}]$ height [km]

Fig. 2. Average trajectories for particular clusters, and trajectories of cluster members for spring clustering of 5 -day trajectories at $5 \mathrm{~km}$. Full 8-day trajectories arriving at $1 \mathrm{~km}, 2.5 \mathrm{~km}$ and $5 \mathrm{~km}$ for days from particular clusters are plotted in pale colours. 
1-day trajectories of cluster members are presented in Fig. 3. Like Fig. 2, Fig. 3 also includes full 8-day trajectories arriving at heights of $1 \mathrm{~km}, 2.5 \mathrm{~km}$ and $5 \mathrm{~km}$ for days from particular clusters.

Clusters 5 (5 members) and 7 (6 members) are northerly clusters. In all these clusters the air passes over Spitsbergen before it reaches Hornsund. The source area for these clusters is mainly the Arctic Ocean and the Nordic seas (Fig. 3), but some trajectories cross Eurasia and the Atlantic Ocean. The trajectories in cluster 5 arrive from the north with a slight easterly component. $\mathrm{N}$ and $\mathrm{E}$ cyclonic circulations are characteristic of this cluster. In cluster 7, trajectories reach Hornsund from the same direction as in cluster 5 , but the transport is much faster. Cyclonic advection from the north with some northerly anticyclonic advection is dominant.

In cluster 10 (4 members), 1-day trajectories come from the NNW at $2.5 \mathrm{~km}$, those at $5 \mathrm{~km}$ from the N. 8-day trajectories are very diverse. In general, the air source areas are similar to those from clusters 4 and 5 (mainly the Arctic Ocean and Nordic seas), but the Atlantic Ocean is reached by trajectories at a height of $1 \mathrm{~km}$. This cluster is dominated by a NW anticyclonic circulation.

Clusters 4 (9 members) and 8 (5 members) are northwesterly. The main source area of cluster 4 is the Arctic Ocean. However, some of these trajectories reach Siberia, Canada and the Atlantic Ocean. Advection on the last day is rapid. Synoptic maps show the dominance of the cyclonic circulation and different geostrophic wind directions (most frequently $\mathrm{N}$ and $\mathrm{NE}$ ) at the moments of trajectory arrival. The source areas of cluster 8 are mainly the North Atlantic and Canada; these air masses from over the Atlantic advected mainly with a NW cyclonic circulation.

Westerly cluster number 1 is the most abundant of all the summer clusters (14 members), but the trajectories in this cluster are not very coherent, coming as they do from many different regions in the Arctic, Canada and Europe. The synoptic situations during AOT measurements are characterised by very low pressure gradients over southern Spitsbergen. In most cases, an anticyclonic wedge or ridge of high pressure and a trough of low pressure were observed. Synoptic maps show no particular dominance of geostrophic wind direction.

Within cluster 3 (8 members), air flows to the Hornsund station from SW (1-day trajectories). 8-day trajectories come mainly from Greenland, the Barents Sea and northern Canada via the Atlantic. Synoptic maps show the dominance of the anticyclonic circulation from the southern sector.

Cluster 9 (7 members) is a local cluster. During the last day before arrival at the station, the air resides near Hornsund. The trajectories are short. 8-day trajectories at $1 \mathrm{~km}$ come mainly from over the Nordic Seas. 8-day trajectories at higher altitudes are very diverse. Types of circulation for this cluster differ, with northern and cyclonic ones dominant.

The 2-member cluster 6 and the 1-element "cluster" 2 can be treated as outliers in the present AOT dataset for the summer.
As already mentioned, the cluster analysis included only clear days and days with low cloud cover. In order to determine the extent to which our cluster classification is representative of all the days of the years under study, our clusters should be compared to the clusters determined for all days, but such an analysis is beyond the scope of this paper. Nonetheless, our classification is consistent with the dominant directions of advection in spring and summer given in the classification by Eneroth et al. (2003) for Ny Ålesund, Spitsbergen. Those authors used a ten-year data set of 5day back-trajectories and applied a single clustering to the whole period, regardless of season. Unlike our classification, the clustering by Eneroth et al. (2003) comprises all days, regardless of cloud cover. Our data set is a very modest one. But despite the differences, both classifications are consistent with respect to the dominant types of advection in spring (anticyclonic from $\mathrm{N}$ to $\mathrm{E}$ or low gradient situations) and summer (advection with cyclonic systems and low gradient situations).

\subsection{Aerosol optical properties of back-trajectory clusters at the Hornsund station}

This section discusses the impact of the individual clusters on aerosol optical properties. Figure $4 \mathrm{a}$ and $\mathrm{b}$ show the average values of AOT and the Ångström exponent for particular clusters from Figs. 2 and 3 along with standard deviations of respective mean values in spring and summer.

\subsubsection{Spring}

In spring (Fig. 4a), the minimum cluster mean AOT is observed for North American clusters: $7 \quad(<$ AOT $>=0.086 \pm 0.009, \quad<\alpha>=1.37 \pm 0.10) \quad$ and $8 \quad(<$ AOT $>=0.087 \pm 0.009, \quad<\alpha>=1.46 \pm 0.08)$ The numbers in parentheses denote average values of AOT and $\alpha$ as well as the standard deviations of the means resulting from the variability within clusters. The maximum cluster mean AOT in spring is found for easterly clusters: $3(<\mathrm{AOT}>=0.123 \pm 0.011,<\alpha>=1.46 \pm 0.07)$ and $9(<$ AOT $>=0.121 \pm 0.007,<\alpha>=1.43 \pm 0.03)$. Generally, the air in clusters of high AOT at $5 \mathrm{~km}$ comes from Asia and Europe (trajectories extend as far as $40^{\circ} \mathrm{N}$ ). This is consistent with the findings of other authors. The differences in average AOT for clusters with high AOT and low AOT are statistically significant at confidence level 0.02 (two-sample unpooled t-test for means).

Clusters $2(<\mathrm{AOT}>=0.107 \pm 0.014, \quad<\alpha>=1.43 \pm 0.06)$ and $4(<$ AOT $>=0.106 \pm 0.017,<\alpha>=1.41 \pm 0.06)$ have an average cluster mean AOT with high in-cluster variability. AOT in cluster 2 is higher than in cluster 7 . The source area for this cluster is farther west, in the direction of Alaska. Moreover, as opposed to cluster 7, the lower trajectories in cluster 2, concentrated over the eastern part of the Arctic basin, often reach western Siberia, which can result in 

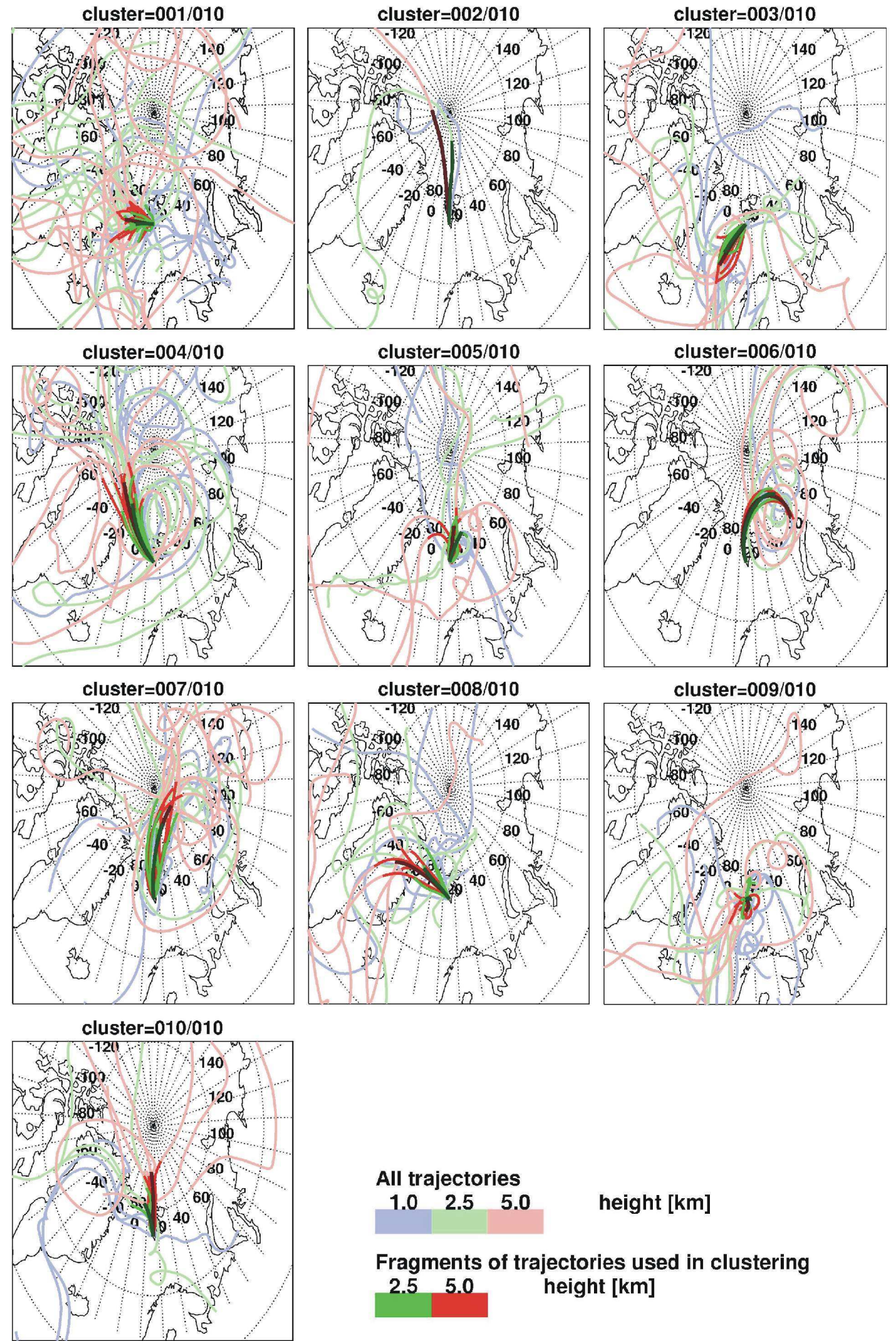

Fig. 3. Average trajectories for particular clusters, and trajectories of cluster members for summer clustering of 1-day trajectories at $2.5+5 \mathrm{~km}$. Full 8-day trajectories arriving at $1 \mathrm{~km}, 2.5 \mathrm{~km}$ and $5 \mathrm{~km}$ for days from particular clusters are plotted in pale colours. 

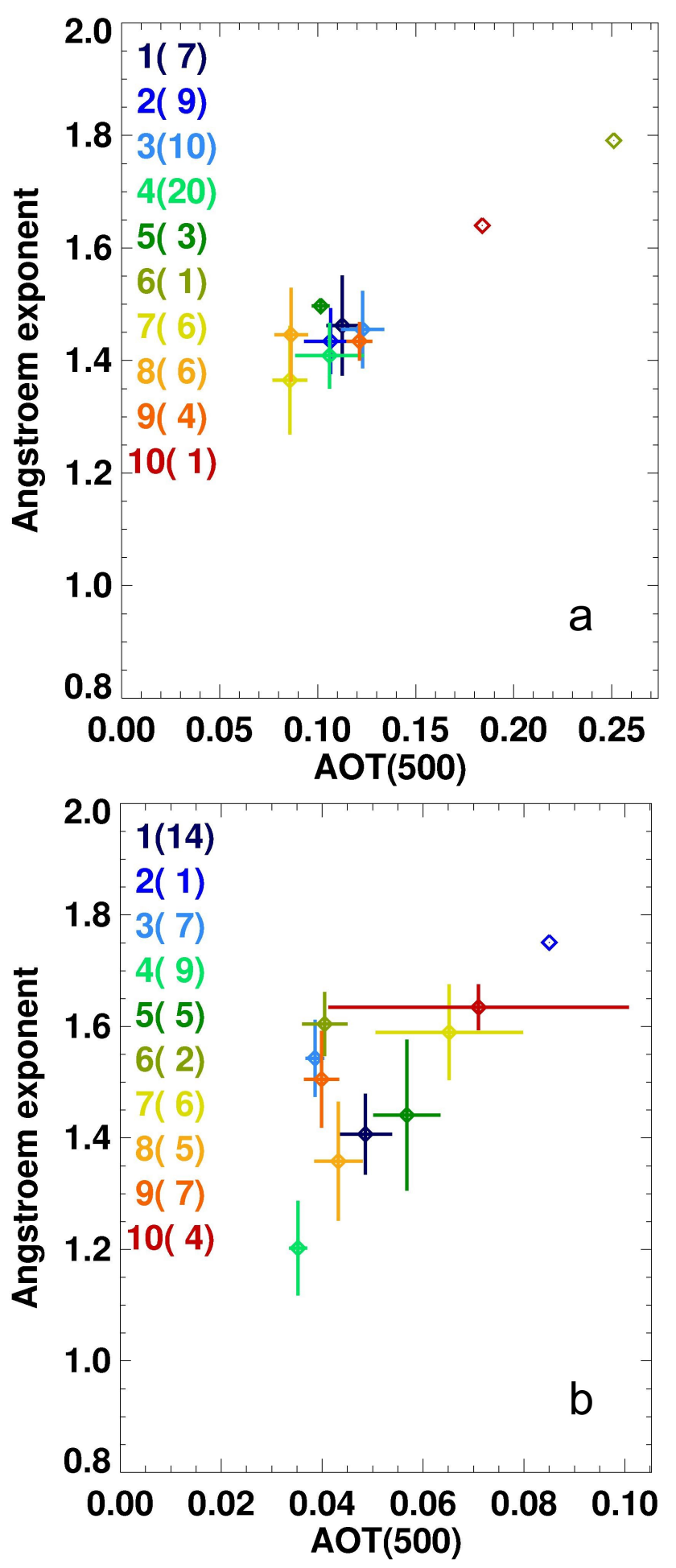

Fig. 4. The average values of AOT and the Ångström exponent for particular clusters together with the respective standard deviations of the mean in spring (a) and summer (b). The numbers in the legend are the cluster numbers and the numbers of cases belonging to particular clusters (in parentheses). a higher AOT. In cluster 4, 5-day trajectories at all levels are concentrated over the Arctic basin, but 8-day trajectories at all levels can reach Eurasia and Alaska and, thus, elevate the cluster mean AOT and increase in-cluster variability. This cluster contains 2 May 2006, an example of smoke advection described by Myhre et al. (2007) (farmland fires in Eastern Europe). Transarctic cluster 1 also exhibits medium cluster mean AOT values $(<$ AOT $>=0.113 \pm 0.008$, $<\alpha>=1.46 \pm 0.09$ ).

The 3-member cluster $5 \quad(<\mathrm{AOT}>=0.102 \pm 0.005$, $<\alpha>=1.50 \pm 0.01$ ) as well as the 1-member clusters 6 (AOT $=0.251, \alpha=1.79)$ and $10(\mathrm{AOT}=0.184, \alpha=1.64)$ can be treated as outliers. Cluster 6 , with its very high AOT, is an example of the extreme smoke event (Myhre et al., 2007; 3 May 2006). In cluster 10 , the trajectory at $5 \mathrm{~km}$ brings air masses from over the Atlantic from over the Atlantic, but the lower ones pass over central Siberia (e.g. near the industrial centre of Norilsk) and they seem to be responsible for the high AOT values (1-member cluster).

The differences between average AOT for medium AOT clusters and high AOT ones as well as between average AOT for medium AOT clusters and clusters with low AOT are statistically insignificant at a confidence level of 0.1. However, different trajectory directions and air mass sources can be characterised by similar AOT values; conversely, clusters with similar trajectories do not have to have very similar optical properties. The aim of this paper was to determine the aerosol optical properties for different advection directions. Therefore, since the cases are grouped according to trajectory character and not optical properties, the wider the clusters (and the smaller their number), the greater the chance that a given cluster includes cases with different features influencing AOT, such as surface type, even if the trajectories are similar.

Differences among clusters in average Ångström exponents are statistically insignificant, except for those between cluster 7 and 5. Cluster 7 shows the lowest value of $\langle\alpha\rangle$. It is the only cluster with the majority of 1-km trajectories residing over the Nordic seas south of Spitsbergen, which are likely to be ice-free in spring.

Clustering indicates that, in the European Arctic, in the spring high AOT values are caused by long-range transport from Europe and Asia. We performed another test to confirm this, distinguishing the following groups among the spring cases:

- none of the trajectories (3 levels) had come into contact with land, except for Greenland,

- at least one trajectory out of the three, arriving simultaneously at the station at different levels, had crossed over North America

- at least one trajectory had crossed Eurasia.

Two subgroups were distinguished in each of these groups: advection over Spitsbergen to the station and marine 
advection to the station. In order to verify the impact of the "source area" on AOT, the average AOT values for these 3 groups were compared. The average AOT for trajectories not impinging on continents, for cases when at least one trajectory "touched" North America and for cases with trajectories from Eurasia were respectively equal to $0.088 \pm 0.009$, $0.085 \pm 0.008$ and $0.1131 \pm 0.006$. The average AOT values for the marine and North America cases are identical, while the differences between the mean AOT for these groups and those for advections from over the Eurasia are statistically significant at a confidence level of 0.1 (two-sample unpooled $\mathrm{t}$-test for means). The impact of direct advection over the station (marine or from over the island) is noticeable but the difference is not statistically significant at a confidence level of 0.1 .

Findings from southern Spitsbergen that long-range advection from Europe and Asia is responsible for AOT variability in spring are in accordance with present knowledge. This is due not only to the location of the main pollution sources, mainly outside the Polar Circle, but also to the easier advection of air masses from over the Atlantic from lower latitudes, which is favoured by the southerly location of the Arctic front. Besides, the relatively low cloud cover and sparse precipitation reduces wet deposition and makes longrange transport more effective in spring. At this time, the local production of aerosols is relatively small since vast areas of Spitsbergen are covered with ice and snow. Sea ice reduces marine aerosol production. In spring, advections from NW-E-S are most frequent, which causes the trajectories to cross a rather uniform surface - mainly snow and ice.

\subsubsection{Summer}

In summer (Fig. 4b), clusters with the lowest mean AOT - the south-westerly cluster 3 ( $<$ AOT $>=0.039 \pm 0.002$, $<\alpha>=1.54 \pm 0.07)$ and the north-westerly cluster 4 $(<\mathrm{AOT}>=0.035 \pm 0.002, \quad<\alpha>=1.20 \pm 0.09) \quad-$ display low variability in AOT, without advections of polluted continental air masses from over the Atlantic. In these clusters, air arrives to Hornsund from off the sea. Although the majority of trajectories are typically Arctic or marine, some of them originate from or pass over continents. In cluster 4, rapid advection from the NW during the last day may have resulted in a relatively low $\alpha$. Cluster 9, a local cluster, is another one with a low AOT and high Ångström exponent ( $<$ AOT $>=0.040 \pm 0.003,<\alpha>=1.51 \pm 0.09$ ). During the last day before arrival at the station, the air resides near Hornsund. Cluster 6 also has a low AOT and high Angström exponent $(<\mathrm{AOT}>=0.041 \pm 0.005,<\alpha>=1.60 \pm 0.06)$ but is represented by only 2 members.

The maximum mean AOT was obtained for "terrestrial" clusters $10 \quad(<\mathrm{AOT}>=0.071 \pm 0.030, \quad \alpha=1.63 \pm 0.04)$, $7 \quad(<\mathrm{AOT}>=0.065 \pm 0.015, \quad<\alpha>=1.59 \pm 0.09) \quad$ and $5(<$ AOT $>=0.057 \pm 0.007,<\alpha>=1.44 \pm 0.14)$. In these clusters, the trajectories typically cross Spitsbergen before reaching Hornsund. The high mean AOT for those clusters is due to the fact that apart from the days with low AOT values $<0.05$, there are cases with high AOT included in these clusters. This also caused a significant standard deviation. In addition, the Ångström exponent in clusters 7 and 10 is high. "Marine" clusters $1 \quad(<$ AOT $>=0.049 \pm 0.005,<\alpha>=1.41 \pm 0.07)$ and $8(<\mathrm{AOT}>=0.043 \pm 0.005,<\alpha>=1.36 \pm 0.11)$ have medium AOT values.

As in spring, the summer differences between the average AOT for medium and high AOT clusters, and between the average AOT for medium and low AOT clusters are statistically insignificant at a confidence level of 0.1 . However, the differences between clusters with low and high cluster average AOT are significant at a confidence level of 0.05 . Cluster 10, however, with its high standard deviation, is an exception.

To recapitulate, the cases of relatively high AOT (AOT $>0.06$ ) occur mainly in the northern, "terrestrial" clusters $(5,7$ and 10$)$, i.e. when air, especially at altitudes of 2.5 and $5 \mathrm{~km}$, crosses Spitsbergen, and also in marine cluster 1. The "terrestrial" clusters $(10,7,5,2)$ have the highest average AOT. Cases of air advection from over the continents (8day trajectories) can be observed in all clusters, but in many instances they are responsible for only a slight increase in AOT, if they have any effect.

Because one-day trajectories can, to some extent, be related to particular air mass source areas, an additional test was performed to ascertain the main reason for AOT variability in summer. The summer AOT cases were divided into groups in the same way as the spring cases. The mean values for trajectories from over North America, Eurasia and the sea are $0.043 \pm 0.004,0.041 \pm 0.002$ and $0.039 \pm 0.008$, respectively. The differences among the averages are not statistically significant at a confidence level of 0.1 . Much higher differences were observed for AOT values for the same source but for trajectories which had crossed Spitsbergen and for those which had reached Hornsund from over the sea. The average summer AOT for cases of advection from over Europe and Asia via the sea were $0.049 \pm 0.005$, while those for advections from over Spitsbergen were $0.072 \pm 0.017$. The null-hypothesis that the means are equal was rejected at a significance level of 0.1. In cases of advection from over North America, the average AOT for marine advections and the ones from over Spitsbergen were $0.038 \pm 0.002$ and $0.060 \pm 0.013$, respectively. The difference is statistically significant at a confidence level of 0.1 . For trajectories not impinging on continents, the difference between direct advection to the station from the sea and from the island side implies that the null-hypothesis (the means are equal) was not rejected at a confidence level of 0.1 (the respective means: $0.037 \pm 0.002,0.043 \pm 0.005)$. The statistical significance of the results is not high, but in order to obtain a better significance, a greater number of data is necessary.

The test shows that for advection from North America and Eurasia from over the ocean AOT values are significantly 


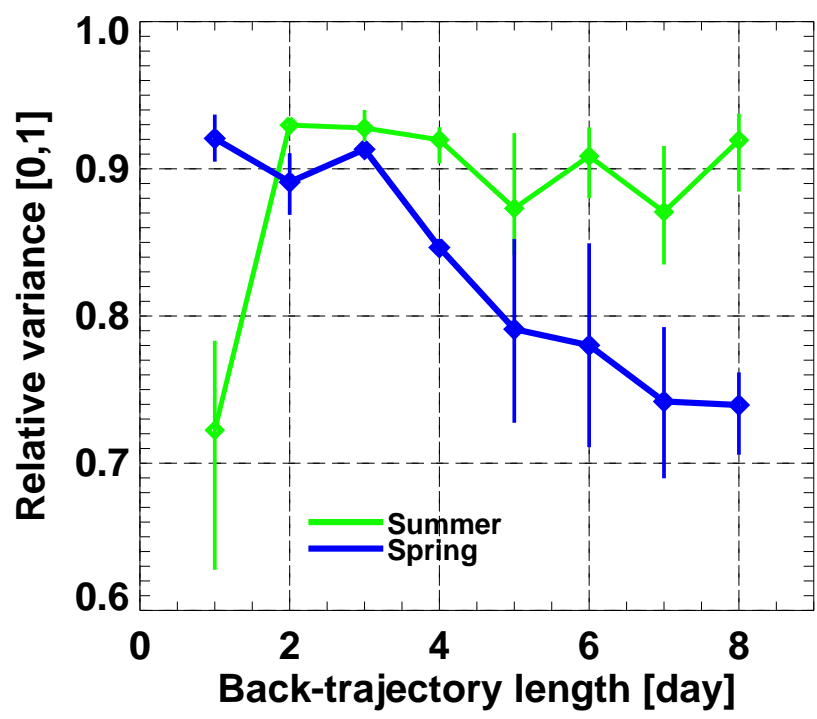

Fig. 5. Comparison of the impact of trajectory length on the relative variance as defined by Eq. (4) in spring and summer and for all the three altitudes above sea level $(1,2.5$ and $5 \mathrm{~km})$ used in the cluster analysis. The vertical lines show ranges of $\operatorname{rv}(\mathrm{AOT})$ resulting from different seed files (minimum and maximum of $\operatorname{rv}(\mathrm{AOT})$ from 3 seed file cases).

lower than for such advections via the island. Moreover, the differences in mean AOT with respect to the direction of direct advection to the station (from the sea or from the island) are more pronounced for trajectories from North America and Eurasia than for trajectories not impinging on the continents. Both the cluster analysis and the test described above suggest that in summer, in contrast to the situation in spring, variability in AOT is caused mainly by local processes of aerosol cleansing, which are more effective while crossing over the ocean owing to the greater cloud cover, probably higher precipitation and marine aerosol cleansing potential (in the boundary layer). The main source of elevated AOT is most probably the same as in spring - long-term advection; but its importance is masked by cleansing processes en route to Hornsund.

Notice that in summer, the AOT variance is several times lower than in spring. The Arctic front moves northwards, which makes the air mass advections from lower latitudes more difficult. Long-range advections are much less common than in spring. The summer transport is slower (Law and Stohl, 2007). Either the advections have an insignificant impact on AOT or their impact is much smaller than in spring. This is due to the increase in wet deposition because of the greater cloud cover and precipitation. In spring, advection comes mainly from the northerly and easterly sectors, whereas in summer, air flowing in from the westerly sector ( $\mathrm{S}-\mathrm{W}-\mathrm{N})$ is dominant. Cleansing intensity is spatially variable. In general, Spitsbergen has a lower cloud cover in summer than the warm seas to the south and west of the island (http://modis-atmos.gsfc.nasa.gov/ MYD08_M3/browse_c5.html). Moreover, ice moves northwards, which facilitates the increased production of marine aerosols contributing to AOT. However, such generation of mainly coarse mode particles due to wave breaking also leads to the formation of additional deposition fluxes of smaller particles from the boundary layer.

\subsection{Importance of aerosol transport in aerosol AOT variability}

In this section, the impact of a number of factors, such as trajectory length, arrival altitude of air advection and a combination of trajectory heights of arrival used in cluster analyses, on relative variance have been analysed for both seasons. The relationships presented below refer to a trajectory division into 10 clusters.

Figure 5 compares the impact of trajectory length on relative variance rv(AOT) in spring and summer and for all the three trajectory arrival heights used in the cluster analysis. Depending on seed file, the clusters applied may differ, even though they describe similar advection directions. The values presented in Figs. 5 and 6 are average values from the results obtained for 3 seed files (see Sect. 2.3). The vertical lines show ranges of AOT relative variance resulting from different seed files (minimum and maximum rv(AOT) from 3 seed file cases).

In spring, $\operatorname{rv}(\mathrm{AOT})$ drops with increasing trajectory length. This suggests that AOT variability at Hornsund is influenced by an air mass history of 8 days or longer. With 10 clusters and 8-day trajectories, the AOT variance drops to about 0.74 of its value if the trajectories are not clustered. Cluster analysis for 1-day trajectories, i.e. the situation in the Hornsund area, explains a maximum of $10 \%$ of variances in spring. In summer, the situation is different. The greatest decrease in AOT variance, $\operatorname{rv}(\mathrm{AOT})<0.72$, is observed with the cluster analysis of 1-day trajectories, which suggests that in summer AOT variability is related mainly to local atmospheric conditions, i.e. cleansing processes en route to Hornsund.

Figure 6 illustrates the influence of air back-trajectory length and trajectory level combination in cluster analysis on rv(AOT). In spring (Fig. 6a), cluster analysis of 8-day advection in the free troposphere (a combination of trajectories arriving at heights of 2.5 and $5 \mathrm{~km}$ ) reduces AOT variance by twice as much as the clustering of trajectories arriving at $1 \mathrm{~km}$ and a combination of altitudes of 1 and $2.5 \mathrm{~km}$. This suggests the dominant part played by free tropospheric advection in AOT variability and can be explained by the longer ranges of higher trajectories and the smaller chances for particles to deposit from high altitudes. With a combination of trajectories arriving at 2 or 3 heights simultaneously, a drop in rv(AOT) is observed with trajectory length increasing from 1 to 8 days. This suggests that a transport of at least 8 days at various levels in the atmosphere is important as regards AOT 
variability. The importance of long-range transport to AOT variability in spring was discussed in the previous section.

Regarding the clustering of trajectories at a single altitude above the Hornsund station, there is a certain trajectory length for which $\mathrm{rv}(\mathrm{AOT})$ is minimum: 5 days for advection at $5 \mathrm{~km}$ and 4 days for an advection arrival height of $1 \mathrm{~km}$. Most probably the cluster analysis of longer "single-level" trajectories is no longer representative of the total (i.e. for all altitudes above the station) advection to the Hornsund station. If AOT is affected by the air mass advection at all the altitudes and the clustering is done for air mass advections at one given altitude, then ignoring the other advection levels adds to the calculation error. We suspect that in the clustering for one level there is some trajectory length, clustering for which is the most representative of advection in the entire atmosphere column.

By dividing our set of trajectories into 10 clusters, we observed the most significant decrease in variance for 5-day air trajectories advecting at an altitude of $5 \mathrm{~km}$. The use of simultaneous advections in the boundary layer and free troposphere increases the variance slightly for the same number of clusters. This is an artifact due to using the same number of clusters with the increasing number of altitude levels employed in the cluster analysis. The more parameters ("degrees of freedom", e.g. the number of levels at which air masses from over the Atlantic arrive) are used in the clustering algorithm, the wider the ranges of particular parameters within a given cluster for the same number of clusters. This may cause the AOT variance to increase. For a sufficiently large dataset, clustering trajectories arriving at several levels simultaneously would produce the best results.

Figure $6 \mathrm{~b}$ presents the impact of trajectory length and the combination of trajectory levels used in cluster analysis on the relative variance of AOT in summer. Regardless of the number of trajectory levels and their combination used in cluster analysis, rv(AOT) is the lowest for 1-day trajectories, which indicates that in summer AOT variability is due mainly to the local situation, local direction and velocity of advection (1-day trajectories). As already discussed in the previous section, this most probably reflects the dependence of the effect of cleansing processes on air arrival direction rather than local aerosol sources.

In cluster analyses of trajectories arriving at $1 \mathrm{~km}$ altitude, $\operatorname{rv}($ AOT) increases along with the increase in trajectory length, whereas in the clustering of a combination of trajectories, including a trajectory in the free troposphere $(5 \mathrm{~km}$, $1+2.5+5 \mathrm{~km})$, a slight drop of rv(AOT) is observed for longer trajectories. This is most probably an effect of long-range transport on AOT variability.

With 10 clusters the variance in AOT mostly decreases with 1-day advections in both the free troposphere and the boundary layer $(\operatorname{rv}(\mathrm{AOT})=0.7)$. The best effect results from a combination of the following levels: $1+5 \mathrm{~km}, 2.5+5 \mathrm{~km}$ and $1+2.5+5 \mathrm{~km}$.
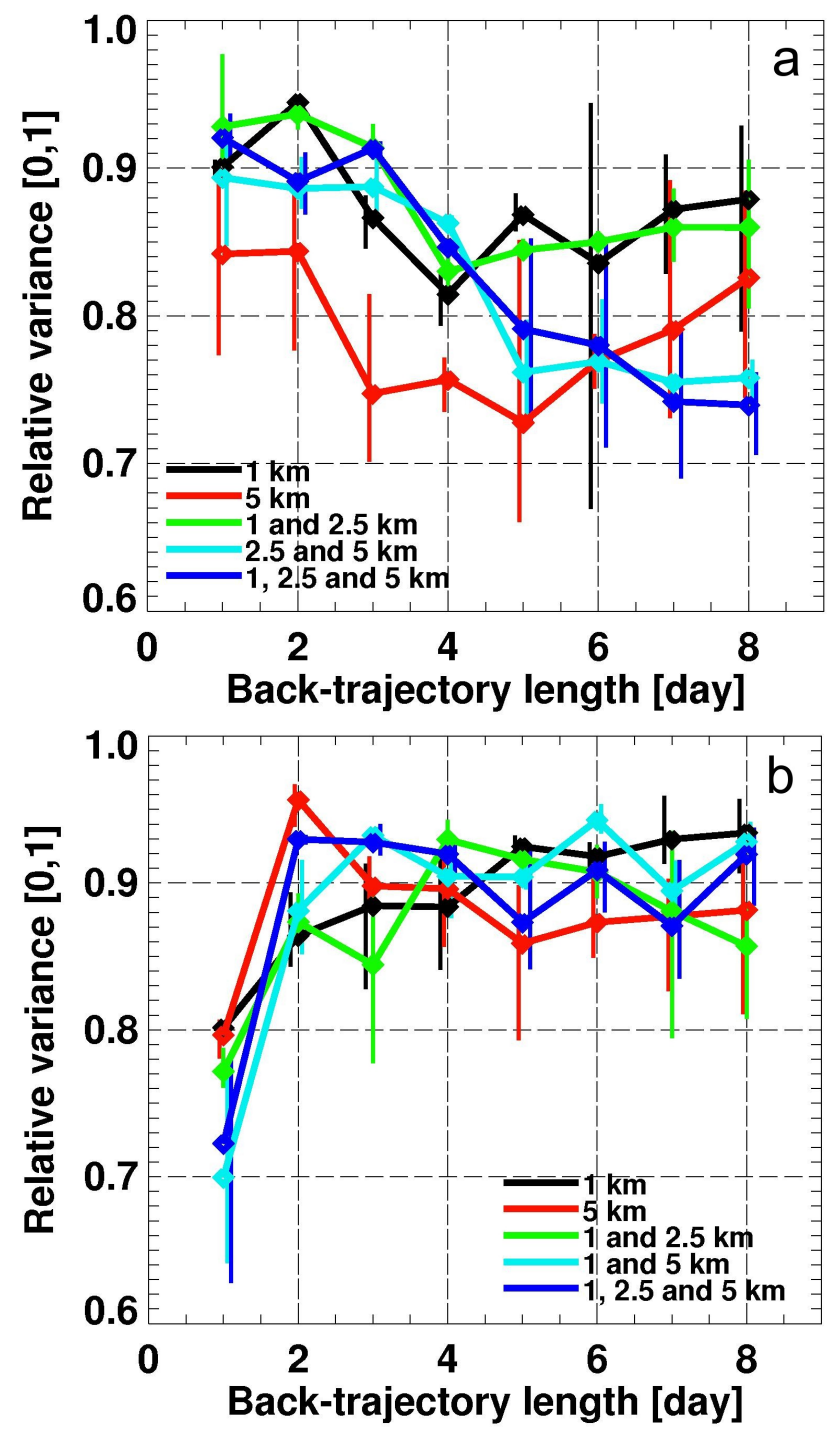

Fig. 6. Impact of trajectory length and trajectory level combination used in cluster analysis on rv(AOT) in spring (a) and summer (b). Colour denotes a trajectory level combination used in clustering and the subsequent calculations of the relative AOT variance. Vertical lines show ranges of rv(AOT) resulting from different seed files.

Even such a robust classification, based on a modest dataset, with a small number of clusters, and without the explicit use of orography, land cover, precipitation, events (e.g. fires) and advecting air height along the trajectory, can explain about $30 \%$ of AOT variances. For comparison, clustering of 3-day back-trajectories ending in Beijing explained from about 25 to $47 \%$ of variance in aerosol optical thickness in Beijing, depending on season (Xia et al., 2007). 
Table 1. Daily mean aerosol properties, meteorological conditions and 5-day back-trajectory clusters during the ASTAR 2007 campaign. $\mathrm{T}_{\text {beg }}$ and $\mathrm{T}_{\text {end }}$ are the respective times of the beginning and the end of the aerosol measurements. $\mathrm{N}$ is the number of observations during a given day. AOT and $\alpha$ are the respective daily means of AOT(500) and $\alpha(440,870)$. $\mathrm{SD}_{\mathrm{AOT}}$ and $\mathrm{SD}_{\alpha}$ are the standard deviations of AOT and $\alpha$. RH, $v$ and dir are the relative humidity, wind speed and wind direction averaged over the time of aerosol measurements. The cluster number $(\mathrm{CN})$ refers to the cluster classification for spring, given in Sects. 3.1.1 and 3.2.1.

\begin{tabular}{rrrrrrrrrrrrr}
\hline $\begin{array}{r}\text { Date } \\
\text { dd.mm.yyyy }\end{array}$ & $\begin{array}{r}\mathrm{T}_{\text {beg }} \\
\mathrm{UTC} \\
{[\mathrm{h}]}\end{array}$ & $\begin{array}{r}\mathrm{T}_{\text {end }} \\
\mathrm{UTC} \\
{[\mathrm{h}]}\end{array}$ & $\begin{array}{r}\text { Julian } \\
\text { day }\end{array}$ & $\mathrm{N}$ & $\mathrm{AOT}$ & $\mathrm{SD}_{\mathrm{AOT}}$ & $\alpha$ & $\mathrm{SD}_{\alpha}$ & $\begin{array}{r}\mathrm{RH} \\
{[\%]}\end{array}$ & $\begin{array}{r}v \\
{[\mathrm{~m} / \mathrm{s}]}\end{array}$ & $\begin{array}{r}\mathrm{dir} \\
{[\mathrm{deg}]}\end{array}$ & $\begin{array}{r}\mathrm{CN} \\
\text { 31 Mar 2007 }\end{array}$ \\
\hline 2 Apr 2007 & 12.53 & 14.57 & 90 & 27 & 0.058 & 0.004 & 1.60 & 0.03 & 61 & 2.7 & 27 & 4 \\
3 Apr 2007 & 7.10 & 12.83 & 92 & 11 & 0.067 & 0.006 & 1.70 & 0.04 & 55 & 0.6 & 90 & 4 \\
9 Apr 2007 & 6.35 & 12.25 & 99 & 26 & 0.091 & 0.017 & 1.78 & 0.06 & 67 & 3.0 & 77 & 8 \\
10 Apr 2007 & 8.00 & 10.10 & 100 & 12 & 0.147 & 0.009 & 1.34 & 0.17 & 76 & 3.0 & 87 & 2 \\
11 Apr 2007 & 12.08 & 15.87 & 101 & 17 & 0.075 & 0.006 & 1.27 & 0.06 & 74 & 9 & 85 & 7 \\
17 Apr 2007 & 5.45 & 13.07 & 107 & 35 & 0.088 & 0.014 & 1.45 & 0.06 & 73 & 1.6 & 90 & 2 \\
\hline
\end{tabular}

\subsection{Data collected during the ASTAR 2007 campaign versus trajectory classification}

The ASTAR 2007 campaign lasted from 31 March to 16 April 2007. Daily mean aerosol properties, meteorological conditions and 5-day back-trajectory clusters during the campaign are presented in Table 1 . The cluster number relates to the cluster classification for spring, given in Sect. 3.2. During the AOT measurements at the Hornsund station relative humidity ranged from 55 to $76 \%$, wind speed did not exceed $3 \mathrm{~m} / \mathrm{s}$, and wind direction was mainly easterly. Only on 10 and 11 April was the mean wind speed 8 and $9 \mathrm{~m} / \mathrm{s}$, respectively. It must be borne in mind that wind direction at the Hornsund station is strongly modified by the latitudinal location of the Hornsund fjord and is, therefore, not representative of air transport in the boundary layer.

During the ASTAR 2007 campaign low AOT values were recorded, ranging from 0.06 to 0.09 , with the exception of 9 April, when $\operatorname{AOT}(500)=0.147$. For comparison, the 4-year mean value of AOT(500) in spring at Hornsund is $0.110 \pm 0.007$ (mean \pm standard deviation of the mean). Assuming that the average of the lowest $20 \%$ of AOT during spring can be treated as the seasonal background, the background AOT is equal to $0.067 \pm 0.002$. With the exception of 9 April, all daily mean AOT values during ASTAR 2007 were within $40 \%$ of the lowest cases of AOT for all spring seasons from 2005 to 2008 . The air back-trajectories belonged to the clusters with low (clusters 7 and 8) and average (clusters 2 and 4) cluster mean AOT (see Sect. 3.2). Apart from the maximum AOT of 9 April, the observed values of AOT were close to or lower than the means for the clusters to which they belong.

9 April is an exception belonging to cluster 2. The daily mean AOT $(=0.147)$ is very high compared to the cluster mean $(<\mathrm{AOT}>=0.107 \pm 0.014)$. The trajectory at $1 \mathrm{~km}$ shows air advection from the Central Siberian Plateau. Even though the 1-km trajectory does not pass over Norilsk, the influence of this region of Siberia cannot be completely ruled out. The copper/nickel mining and smelting complex near Norilsk is a big source of pollutants, including sulphur dioxide (Kashulina et al., 2003).

This example shows that although long-range transport in the free troposphere is dominant in spring, several trajectory levels should be used to analyse the impact of long-range transport on aerosol optical properties.

\section{Conclusions}

In spring, the variability in AOT values over the Hornsund station is influenced by a history of air at least 8 days long, which is advected both in the free troposphere and in the boundary layer. That free tropospheric advection is dominant is confirmed by low values of rv(AOT) for the cluster classification of the combined 2.5 and $5 \mathrm{~km}$ trajectories. 1day trajectories explain only $10 \%$ of AOT variance. In summer, as in spring, long-range advection from Europe and Asia is mainly responsible for the increase in AOT. However, in contrast to spring, the importance of the source is masked by local conditions - spatial variability in cleansing intensity en route to the station. In cases of advection from North America and Eurasia from over the ocean, AOT values are significantly lower than when such advections approach via the island. Moreover, the differences in mean AOT related to the direction of direct advection to the station (from the sea or from the island) are more pronounced for trajectories from North America and Eurasia than for trajectories not impinging on any continents. That is why we think that the summer variability in AOT is influenced by local cleansing processes rather than local aerosol sources.

The division of cases versus the trajectory type reduces the variance of AOT. The magnitude of the reduction depends 
on trajectory length, its altitude of arrival, the number of altitudes considered in the cluster analysis and the number of clusters. With 10 clusters and the AOT data recorded, the greatest decrease in variance (about 30\%) was obtained with clustering of 5-day trajectories at $5 \mathrm{~km}$ for spring and 1-day trajectories at $2.5+5 \mathrm{~km}$ for summer.

In spring, the most abundant clusters at Hornsund are the ones of average (cluster $4,<$ AOT $>=0.106 \pm 0.017$; cluster 2, $<$ AOT $>=0.107 \pm 0.014$, cluster $1<$ AOT $>=0.113 \pm 0.008$ ) and high (cluster $3,<\mathrm{AOT}>=0.123 \pm 0.011$ ) cluster mean AOT. There are $61 \%$ of such cases in total. For these clusters advection from the northerly sector (from NW to NE) is typical. In clusters with high AOT (clusters 3, 9, 6 and 10), air at $5 \mathrm{~km}$ comes mainly from Asia and Europe (trajectories reach down to $40^{\circ} \mathrm{N}$ ); the lower trajectories bring in air mainly from over the Arctic Ocean and the Barents Sea, but also from central and eastern Siberia. This is consistent with findings by other authors for other parts of the Arctic.

In summer, the most abundant clusters at Hornsund are numbers $1 \quad(<$ AOT $>=0.049 \pm 0.005)$, $4 \quad(<\mathrm{AOT}>=0.035 \pm 0.002), \quad 3 \quad(<\mathrm{AOT}>=0.039 \pm 0.002)$ and $9(<\mathrm{AOT}>=0.040 \pm 0.003)$. In all, there are $62 \%$ of such cases. Except for number 1, all these clusters exhibit low AOT values. Advection from the western sector (from $\mathrm{S}$ to $\mathrm{N}$ ) is typical of them. The so-called events (i.e. cases with high daily mean AOT) occur mainly in the northern, "terrestrial" clusters (clusters 5, 7 and 10), i.e. when air masses from over the Atlantic cross Spitsbergen, especially at altitudes of 2.5 and $5 \mathrm{~km}$, and also in the marine cluster 1 . The "terrestrial" clusters $(10,7,5,2)$ have the highest average AOT $(0.071 \pm 0.030,0.065 \pm 0.015, \quad 0.057 \pm 0.007$ and 0.085 , respectively). Cases of advection from over the continents (8-day trajectories) can be observed in all clusters, but in many instances they are responsible for only a slight increase in the AOT values, if they have any effect at all.

The statistical significance of the results is not high: to achieve a better significance, greater numbers of data are necessary. However, in view of the specific features of the applied sun-photometric measurements of AOT (unobscured sun required), the Arctic conditions, as well as the rapid changes in climate, the collection of a large, consistent data set may be impossible. We are, therefore, of the opinion that despite the relatively small number of data, this analysis has been worthwhile.

During the ASTAR 2007 campaign low AOT values were recorded, ranging from 0.06 to 0.09 , with the exception of 9 April, when AOT $(500)=0.147$. These values are lower than the 4-year mean AOT(500) for spring $(0.110 \pm 0.007$; mean \pm standard deviation of the mean) at Hornsund. The backtrajectories belonged to the clusters of low (clusters 7 and 8) and average (clusters 2 and 4) cluster mean AOT (compare Sect. 3.2). Apart from the maximum AOT of 9 April 2007, the observed AOT values were close to or lower than the means for the clusters to which they belong.
Acknowledgements. The authors gratefully acknowledge the NOAA Air Resources Laboratory (ARL) for the provision of the HYSPLIT transport and dispersion model and the READY website (http://www.arl.noaa.gov/ready.html) used in this publication. The authors thank anonymous reviewers for their very significant contribution to the improvement of this paper. The authors would also like to thank the Hornsund station management for their assistance with these studies during the ASTAR 2007 campaign. This research was carried out within the framework of Polish Post-doctoral Research Project NN307315436 funded by the Polish Ministry of Science and Higher Education and partly within the framework of Polish National Grant MACS/AERONET/59/2007 and Polish Research Project NN306315536.

Edited by: M. Wendisch

\section{References}

Abdalmogith, S. S. and Harrison, R. M.: The use of trajectory cluster analysis to examine the long-range transport of secondary inorganic aerosol in the UK, Atmos. Environ., 39(35), 6686-6695, 2005.

Dorling, S. R., Davies, T. D., and Pierce, C. E.: Cluster analysis: a technique for estimating the synoptic meteorological controls on air and precipitation chemistry - method and applications, Atmos. Environ., 26A(14), 2575-2581, 1992.

Draxler, R. R. and Rolph, G. D.: HYSPLIT (HYbrid SingleParticle Lagrangian Integrated Trajectory) Model, access via NOAA ARL READY Website, http://www.arl.noaa.gov/ready/ hysplit4.html, last access: 25 January 2010, Silver Spring, MD, NOAA Air Resources Laboratory, 2003.

Draxler, R., Stunder, B., Rolph, G., Stein, A., and Taylor, A.: HYSPLIT4 User's Guide, Version 4.9, http://www.arl.noaa.gov/ documents/reports/hysplit_user_guide.pdf, last access: 25 January $2010,2009$.

Eneroth, K., Kjellstrom, E., and Holmen, K.: A trajectory climatology for Svalbard; investigating how atmospheric flow patterns influence observed tracer concentrations, Phys. Chem. Earth, 28(28-32), 1191-1203, 2003.

Engvall, A.-C., Krejci, R., Ström, J., Treffeisen, R., Scheele, R., Hermansen, O., and Paatero, J.: Changes in aerosol properties during spring-summer period in the Arctic troposphere, Atmos. Chem. Phys., 8, 445-462, 2008, http://www.atmos-chem-phys.net/8/445/2008/.

Generoso, S., Bey, I., Attié, J.-L., and Bréon, F.-M.: A satelliteand model-based assessment of the 2003 Russian fires: Impact on the Arctic region, J. Geophys. Res., 112, D15302, doi:10.1029/2006JD008344, 2007.

Gogoi, M. M., Moorthy, K. K., Babu, S. S., and Bhuyan, P. K.: Climatology of columnar aerosol properties and the influence of synoptic conditions: First-time results from the northeastern region of India, J. Geophys. Res., 114, D08202, doi:10.1029/2008JD010765, 2009.

Heidam, N. Z., Christensen, J., Wahlin, P., and Skov, H.: Arctic atmospheric contaminants in NE Greenland: levels, variations, origins, transport, transformations and trends 1990-2001, Sci. Total. Environ., 331, 5-28, 2004. 
Herber, A., Thomason, L. W., Gernandt, H., Leiterer, U., Nagel, D., Schulz, K. H., Kaptur, J., Albrecht, T., and Notholt, J.: Continuous day and night aerosol optical depth observations in the Arctic between 1991 and 1999, J. Geophys. Res., 107(D10), 4097, doi:10.1029/2001JD000536, 2002.

Hillamo, R., Kerminen, V.-M., Aurela, M., Mäkelä, T., Maenhaut, W., and Leek, C.: Modal structure of chemical mass size distribution in the high Arctic aerosol, J. Geophys. Res., 106(D21), 27555-27571, 2001

Kalnay, E., Kanamitsu, M., Kistler, R., Collins, W., Deaven, D., Gandin, L., Iredell, M., Saha, S., White, G., Woollen, J., Zhu, Y., Leetmaa, A., Reynolds, R., Chelliah, M., Ebisuzaki, W., Higgins, W., Janowiak, J., Mo, K. C., Ropelewski, C., Wang, J., Jenne, R., and Joseph, D.: The NCEP/NCAR 40-year reanalysis project, B. Am. Meteorol. Soc., 77, 437-470, 1996.

Kashulina, G., Reimann, C., and Banks, D.: Sulphur in the Arctic environment (3): environmental impact, Environ. Pollut., 124, 151-171, 2003.

Katragkou, E., Kazadzis, S., Amiridis, V., Papaioannou, V., Karathanasis, S., and Melas, D.: $\mathrm{PM}_{10}$ regional transport pathways in Thessaloniki, Greece, Atmos. Environ., 43(5), 10791085, 2009.

Khattatov, V. U., Tyabotov, A. E., Alekseyev, A. P., Postnov, A. A., and Stulov, E. A.: Aircraft lidar studies of the Arctic haze and their meteorological interpretation, Atmos. Res., 44(1-2), 99$111,1997$.

Law, K. S. and Stohl, A.: Arctic air pollution: Origins and impacts, Science, 315(5818), 1537-1540, 2007.

Leck, C. and Bigg, E. K.: Biogenic particles in the surface microlayer and overlaying atmosphere in the central Arctic Ocean during summer, Tellus B, 57, 305-316, 2005.

Lin, C. J., Cheng, M. D., and Schroeder, W. H.: Transport patterns and potential sources of total gaseous mercury measured in Canadian high Arctic in 1995, Atmos. Environ., 35(6), 11411154,2001

Mulcahy, J. P., O’Dowd, C. D., Jennings, S. G., and Ceburnis, D.: Significant enhancement of aerosol optical depth in marine air under high wind conditions, Geophys. Res. Lett., 35, L16810, doi:10.1029/2008GL034303, 2008.

Myhre, C. L., Toledano, C., Myhre, G., Stebel, K., Yttri, K. E., Aaltonen, V., Johnsrud, M., Frioud, M., Cachorro, V., de Frutos, A., Lihavainen, H., Campell, J. R., Chaikovsky, A. P., Shiobara, M., Welton, E. J., and Tørseth, K.: Regional aerosol optical properties and radiative impact of the extreme smoke event in the European Arctic in spring, Atmos. Chem. Phys., 7, 5899-5915, 2007, http://www.atmos-chem-phys.net/7/5899/2007/.

Nagel, D., Herber, A., Thomason, L. W., and Leiterer, U.: Vertical distribution of the spectral aerosol optical depth in the Arctic from 1993 to 1996, J. Geophys. Res., 103(D2), 1857-1870, 1998.

Niedźwiedź, T.: A calendar of atmospheric circulation types for Spitsbergen, a computer file, University of Silesia, Department of Climatology, Sosnowiec, Poland, 2009.

O’Neill, N. T., Eck T. F., Smirnov, A., Holben, B. N., and Thulasiraman, S.: Spectral discrimination of coarse and fine mode optical depth, J. Geophys. Res., 108(D17), 4559, doi:10.1029/2002JD002975, 2003.
Owega, S., Khan, B. U. Z., Evans, G. J., Jervis, R. E., and Fila, M.: Identification of long-range aerosol transport patterns to Toronto via classification of back trajectories by cluster analysis and neural network techniques, Chemometr. Intell. Lab., 83(1), 26-33, 2006.

Petelski, T. and Piskozub, J.: Vertical coarse aerosol fluxes in the atmospheric surface layer over the North Polar Waters of the Atlantic, J. Geophys. Res., 111, C06039, doi:10.1029/2005JC003295, 2006.

Quinn, P. K., Miller, T. L., Bates, T. S., Ogren, J. A., Andrews, E., and Shaw, G. E.: A 3 year record of simultaneously measured aerosol chemical and optical properties at Barrow, Alaska, J. Geophys. Res., 107(D11), 4130, doi:10.1029/2001JD001248, 2002.

Quinn, P. K., Shaw, G., Andrews, E., Dutton, E. G., Ruoho-Airola T., and Gong, S. L.: Arctic haze: current trends and knowledge gaps, Tellus, 59B, 99-114, 2007.

Rozwadowska, A., Petelski, T., and Zielinski, T.: Aerosol measurements in Hornsund during XXIX PAS polar expedition, Problemy Klimatologii Polarnej, 18, 161-170, 2008.

Rozwadowska, A. and Sobolewski, P.: Variability in aerosol optical properties at Hornsund, Spitsbergen, submitted for publication in Oceanologia, 2010.

Smirnov, A., Holben, B. N., Eck, T. F., Dubovik, O., and Slutsker, I.: Cloud-screening and quality control algorithms for the AERONET database, Remote Sens. Environ., 73, 337-349, 2000.

Stohl, A., Andrews, E., Burkhart, J. F., Forster, C., Herber, A., Hoch, S. W., Kowal, D., Lunder, C., Mefford, T., Ogren, J. A., Sharma, S., Spichtinger, N., Stebel, K., Stone, R., Stroem, J., Tørseth, K., Wehrli, C., and Yttri, K. E.: Pan-Arctic enhancements of light absorbing aerosol concentrations due to North American boreal forest fires during summer 2004, J. Geophys. Res., 111, D22214, doi:10.1029/2006JD007216, 2006.

Stohl, A., Eckhardt, S., Forster, C., James, P., and Spichtinger, N.: On the pathways and timescales of intercontinental air pollution transport, J. Geophys. Res., 107(D23), 4684, doi:10.1029/2001JD001396, 2002.

Stone, R. S., Anderson, G. P., Andrews, E., Dutton, E. G., Shettle, E. P., and Berk, A.: Incursions and radiative impact of Asian dust in northern Alaska, Geophys. Res. Lett., 34, L14815, doi:10.1029/2007GL029878, 2007.

Toledano, C., Cachorro, V. E., de Frutos, A. M., Torres, B., Berjon, A., Sorribas, M., and Stone, R. S.: Airmass Classification and Analysis of Aerosol Types at El Arenosillo (Spain), J. Appl. Meteorol. Clim., 48(5), 962-981, 2009.

Tomasi, C., Vitale, V., Lupi, A., Di Carmine, C., Campanelli, M., Herber, A., Treffeisen, R., Stone, R. S., Andrews, E., Sharma, S., Radionov, V., von Hoyningen-Huene, W., Stebel, K., Hansen, G. H., Myhre, C. L., Wehrli, C., Aaltonen, V., Lihavainen, H., Virkkula, A., Hillamo, R., Stroem, J., Toledano, C., Cachorro, V. E., Ortiz, P., de Frutos, A. M., Blindheim, S., Frioud, M., Gausa, M., Zielinski, T., Petelski, T., and Yamanouchi, T. Aerosols in polar regions: A historical overview based on optical depth and in situ observations, J. Geophys. Res., 112, D16205, doi:10.1029/2007JD008432, 2007. 
Treffeisen, R., Tunved, P., Ström, J., Herber, A., Bareiss, J., Helbig, A., Stone, R. S., Hoyningen-Huene, W., Krejci, R., Stohl, A., and Neuber, R.: Arctic smoke - aerosol characteristics during a record smoke event in the European Arctic and its radiative impact, Atmos. Chem. Phys., 7, 3035-3053, 2007, http://www.atmos-chem-phys.net/7/3035/2007/.

Xia, X., Chen, H., and Zhang, W.: Analysis of the dependence of column-integrated aerosol properties on long-range transport of air masses from over the Atlantic in Beijing, Atmos. Environ., 41(36), 7739-7750, 2007.
Yan, P., Tang, J., Huang, J., Mao, J. T., Zhou, X.J., Liu, Q., Wang, Z. F., and Zhou, H. G.: The measurement of aerosol optical properties at a rural site in Northern China, Atmos. Chem. Phys., 8, 2229-2242, 2008,

http://www.atmos-chem-phys.net/8/2229/2008/. 